\title{
FIELD MEASUREMENTS OF BEDFORMS IN A RIP CHANNEL ON A MACRO-TIDAL BEACH
}

\author{
Antony Thorpe ${ }^{1}$, Jon Miles, Gerd Masselink, Paul Russell, Tim Scott and Martin Austin
}

A Sand Ripple Profiler (SRP) was deployed in a rip channel on a dissipative sandy beach to measure bedform height $(\Delta)$, length $(\lambda)$ and migration rate $\left(M_{r}\right)$ throughout a macro-tidal cycle with an offshore significant wave height of 0.7 $\mathrm{m}$ and peak period of $10 \mathrm{~s}$. At lower tidal elevations in the strong offshore flow of the rip current $($ maximum $=0.4$ $\mathrm{m} / \mathrm{s})$ bedforms $(\Delta=0.15 \mathrm{~m}, \lambda=3 \mathrm{~m})$ were found to migrate offshore $\left(M_{r}=0.21 \mathrm{~m} / \mathrm{hr}\right)$. Outside of active rip current conditions (water depth $(h)=>\sim 2.5 \mathrm{~m})$ bedforms were found to be of smaller scale $(\Delta=0.09-0.12 \mathrm{~m}, \lambda=1-1.2 \mathrm{~m})$ migrating onshore at a rate of $0.35 \mathrm{~m} / \mathrm{hr}$ at mid tide $(h=3.3 \mathrm{~m})$ and $0.03 \mathrm{~m} / \mathrm{hr}$ at high tide $(h=6.3 \mathrm{~m})$. Onshore migration rates were found to increase with increased wave skewness and velocity variance.

Keywords: rip currents, bedforms, megaripples

\section{INTRODUCTION}

Rip currents are a unique feature of the nearshore environment exhibiting a channel of strong, quasi-steady, offshore directed flow (in the order of $0.5 \mathrm{~m} / \mathrm{s}$ ) that dissects the wave dominated surfzone and dissipates beyond the breaker zone (MacMahan et al., 2005). Rips are a mass balance response to wave induced onshore transport. Wave breaking is focused on sandbars and minimized in the rip channel; as a consequence of this, water travels alongshore in feeder channels before flowing seaward within the rip neck (MacMahan et al., 2006). They are typically found at lower tidal elevations where they are associated with the bar/rip morphology of intermediate state beaches (Brander, 1999a).

Megaripples are large ripples or small dunes with heights $(\Delta)$ of $0.1-0.5 \mathrm{~m}$ and lengths $(\lambda)$ of $1-$ $5 \mathrm{~m}$ (Gallagher, 2003). They are generally present within the nearshore environment. Field observations suggest that megaripples exist in rip currents (Aagaard et al., 1997), migrate offshore (Greenwood \& Davidson-Arnott, 1979) and that they are current dominated (Nielsen, 1992). Sherman et al. (1993) observed megaripples in a rip feeder channel by visually measuring a pre-selected megaripple with a 'meter long aluminium comb'. They observed lunate bedforms of megaripple dimension $(\Delta=0.16 \mathrm{~m}, \lambda=1.6 \mathrm{~m})$ migrating at $0.99 \mathrm{~m} / \mathrm{hr}$ in the direction of flow.

Gallagher et al. (1998) found megaripples $(\Delta=0.2-0.3 \mathrm{~m}, \lambda=2-5 \mathrm{~m})$ present 60 percent of the time in the surfzone (in a trough where $h=1.5-2 \mathrm{~m}$ ) during a 6 week field work campaign. The megaripple generally took the form of oval shaped holes and occurred under a wide range of wave conditions $\left(H_{s}=0.5-4 \mathrm{~m}\right)$. Onshore migration was attributed to wave skewness with typical migration rates of $0.3 \mathrm{~m} / \mathrm{hr}$ (maximum $=1.5 \mathrm{~m} / \mathrm{hr}$ ). Gallagher (2003) proposed that megaripples found in the combined flow environment of the surfzone were dynamically similar to asymmetric, steady flow features present in rivers, estuaries and deserts.

In this study, results are presented of bedform dynamics measured in a rip channel on an exposed sandy beach over a macro-tidal cycle. The large change in water level at the site allows a comparison between bedform dynamics at lower tidal elevations when there is an active rip current with those at higher tidal elevations when the rip becomes inactive.

\section{STUDYSITE \& METHODOLOGY}

\section{Study Site}

The study site was Perranporth, a $3.5 \mathrm{~km}$ long beach (Figure 1) located on the North Coast of Cornwall, UK (Figure 2). 


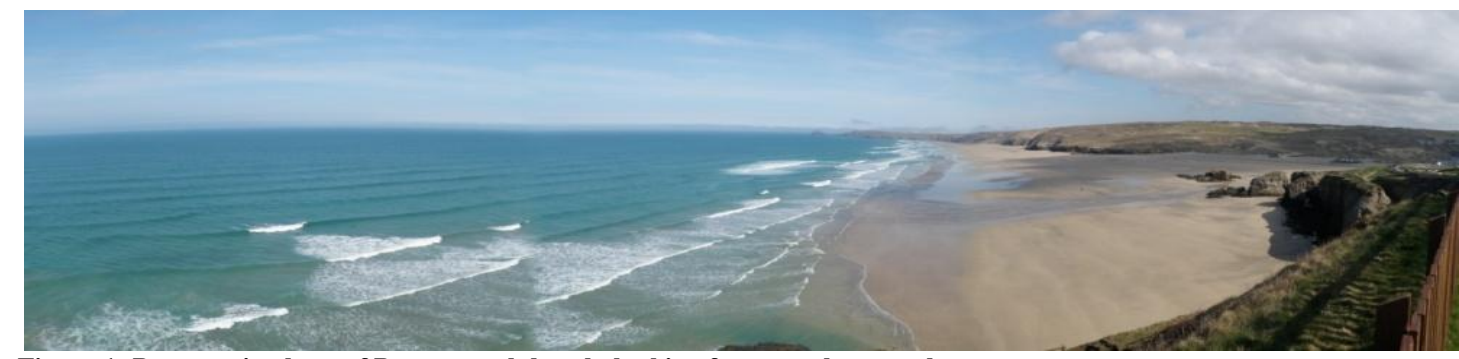

Figure 1: Panoramic photo of Perranporth beach, looking form south to north.

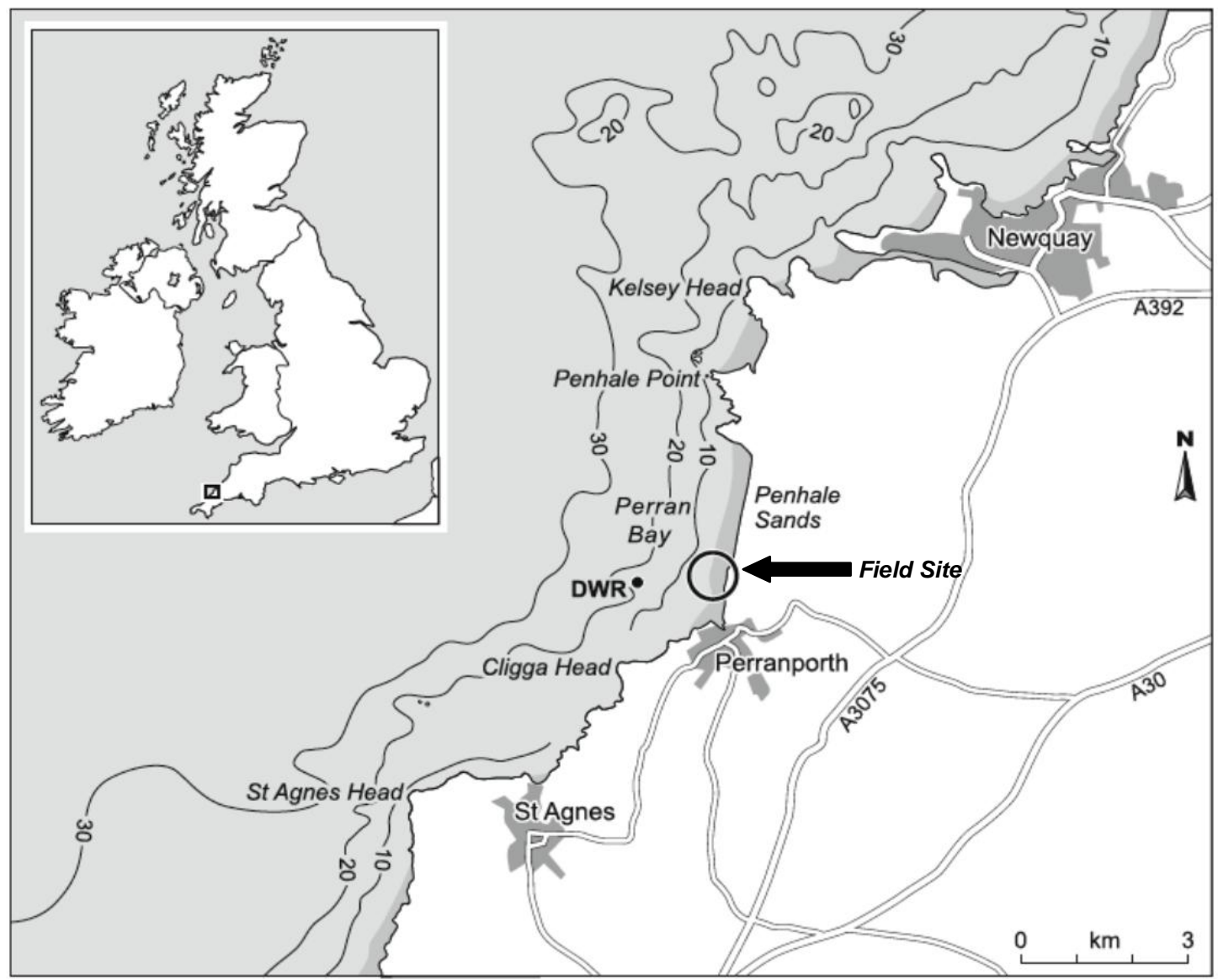

Figure 2: Map showing location of the study site and within the UK the location of the directional wave rider buoy (DWR) (Austin et al., 2010).

Perranporth is a highly energetic beach with an annual significant wave height $\left(H_{s}\right)$ of $1.6 \mathrm{~m}$ and a peak period $\left(T_{p}\right)$ of $10.5 \mathrm{~s}(\mathrm{CCO}, 2012)$. It faces west-northwest, is exposed to Atlantic swell and also receives locally generated wind waves. It is a macro-tidal beach with a mean spring range of $6.3 \mathrm{~m}$ and consists of medium sized sand $\left(D_{50}=0.28-0.34 \mathrm{~mm}\right)$. The beach lies on the boundary of the intermediate and dissipative classifications with pronounced bar/rip morphology on a seasonal time scale (Austin et al., 2010).

Figure 3 shows a time-averaged image captured with an ARGUS camera of Perranporth beach at spring low tide at the time of the experiments described in this paper. The rhythmic nature of the bar/rip system is evident throughout the length of the beach. The rip used for the study and the location of the instrumentation is marked on the image. This rip was chosen because it offered a clearly defined channel with offshore flow dissecting the intertidal bar. 


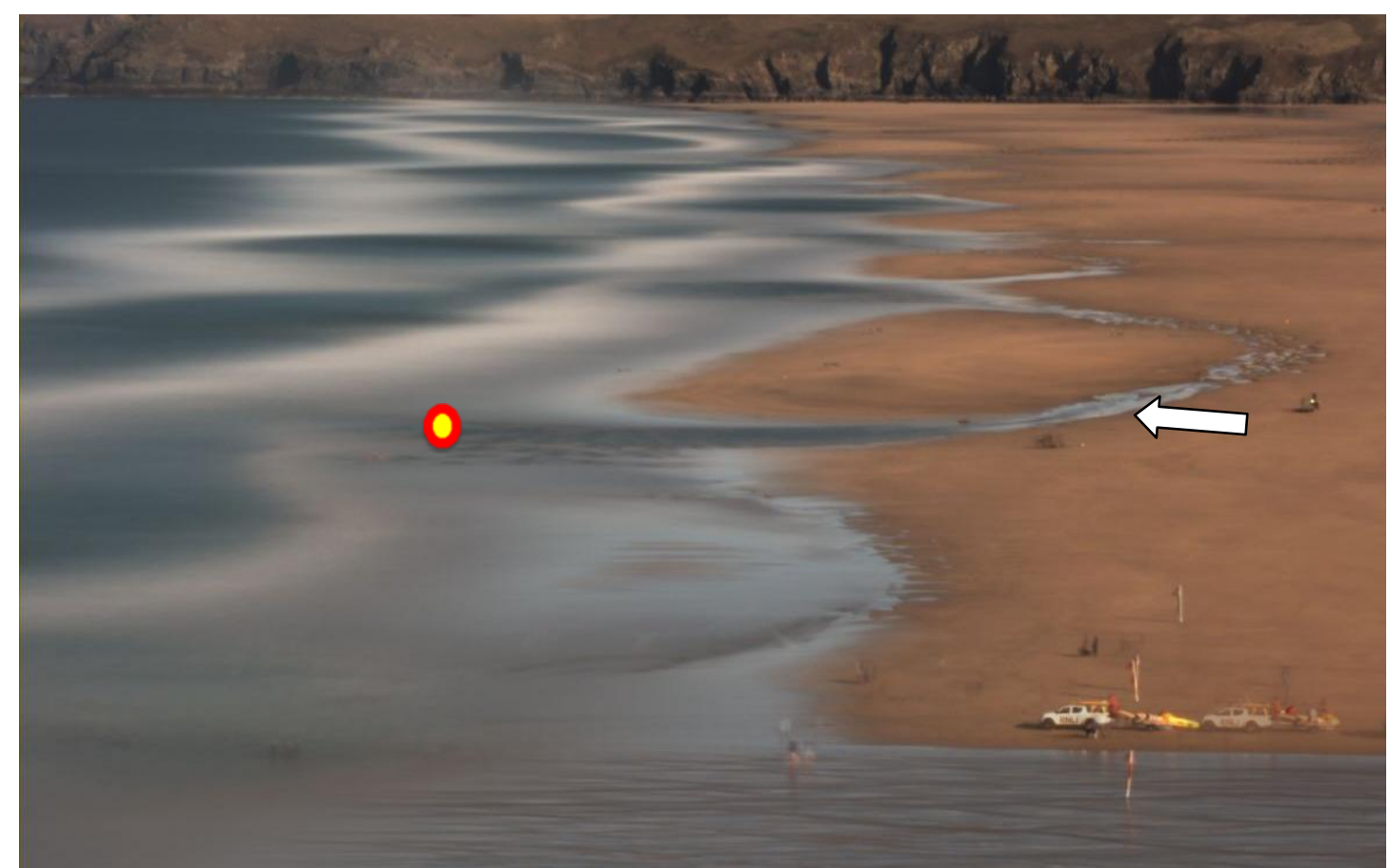

Figure 3: Time averaged image of bar-rip morphology at Perranporth beach (arrow marks rip system used in study; circle marks position of instrumentation).

\section{Methodology}

Offshore wave data were collected from a Directional Wave Rider (DWR) wave buoy located approximately $1 \mathrm{~km}$ offshore (see Figure 2) of the study site (CCO, 2012). In-situ data were collected using a range of instruments secured to a mobile rig. The rig was assembled prior to deployment and carried into the rip channel at spring low tide.

The flow velocities, waves and tidal elevation in the rip channel were recorded with a Nortek Vector 3D-Acoustic Doppler Velocimeter (ADV) fitted with an external pressure transducer (PT). The head of the ADV was carefully aligned to measure cross-shore and longshore flows at a height of 0.55 $\mathrm{m}$ above the bed. The PT, used to measure wave statistics and tidal elevation was housed in the ADV casing unit with the sensor positioned at a height of $0.2 \mathrm{~m}$ above the bed. Data from both instruments were logged autonomously at $8 \mathrm{~Hz}$.

A Sand Ripple Profiler (SRP) was used to measure bedform dynamics. The SRP is a pencil beam sonar scanner that collects data as a range and angle from the scanner, for analysis this is processed to obtain an ' $x$ ' (cross-shore distance) and ' $z$ ' (distance below the scanner) co-ordinate system. The data can be post-processed to produce a profile of the bed from which $\Delta, \lambda$ and $M_{r}$ can be deduced. The SRP was aligned to scan in the cross-shore direction, and was positioned $0.9 \mathrm{~m}$ above the bed with a horizontal resolution of $14 \mathrm{~mm}$ directly below the scanner. The data logger was programmed to log autonomously scanning the bed once every minute. The SRP does not give reliable data in breaking waves, due to excessive amounts of bubbles in the water column. Bedform data are therefore only available for water depths of over approximately $1 \mathrm{~m}$. 


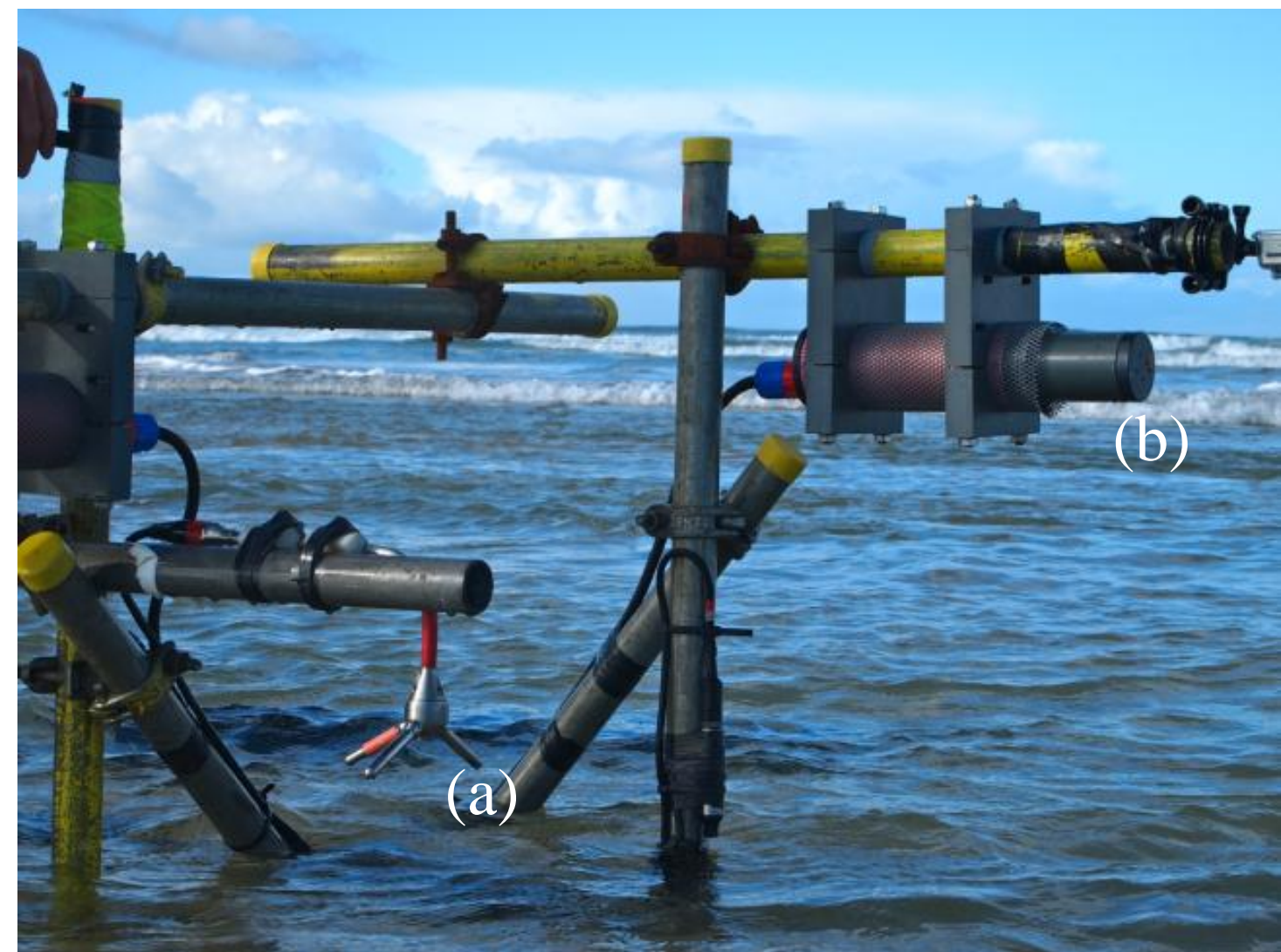

Figure 4: Rig design and position of instruments; (a) ADV head, (b) SRP. The picture was taken at low tide; at mid and high tide the rig is completely submerged.

The SRP data was post processed by first applying a five minute averaging routine in which five consecutive scans were combined. Spurious ' $z$ ' axis data points were identified as those with a difference of $50 \mathrm{~mm}$ or over in elevation from neighbouring points and were removed. The gaps in the data this created were treated by applying linear interpolation over a $2 \mathrm{~m}$ range.

Bedform height was obtained by measuring the difference between crest and trough height of the same bedform. A value for half a wavelength was obtained by finding the cross-shore distance between the crest and trough, this value was then doubled. Bedform wavelength was measured in such a way as the bedform length scale is occasionally similar or greater than the SRP footprint; therefore the complete bedform is not always visible in the SRP scan. The limitation of this is that the wavelength may be under or overestimated if the bedform is not symmetrical. Migration rate was calculated measuring the distance of crest-crest or trough-trough positions over consecutive scans and dividing by the elapsed time.

Intertidal surveys of the beach elevation were carried out at low tide using a Real Time Kinematic GPS (RTK-GPS) mounted on an All-Terrain Vehicle (ATV). Sub-tidal surveys were carried out using a RTK-GPS in conjunction with a single beam echo sounder mounted on a Jet Ski, overlapping the intertidal surveys. The two sets of survey data were combined and interpolated onto a normal grid and fitted to a local co-ordinate system (Austin et al, 2010).

Lagrangian drifters, based on a design by Schmit (2003), were used to measure rip flows and to identify the overall location of the rip current.. The drifters were fitted with GPS receivers and data loggers capable of recording raw carrier phase satellite data at $1 \mathrm{~Hz}$, which were subsequently processed against a survey grade base station. The data provided estimates of rip flow with a positional accuracy of $<0.4 \mathrm{~m}$ and an accuracy of the flow velocity estimates of $0.01 \mathrm{~m} / \mathrm{s}$ (Austin et al., 2010).

\section{RESULTS}

\section{Environmental Conditions}

Data were collected over six tidal cycles in October 2011. Data in this paper are presented from two tidal cycles over the $14^{\text {th }}$ and $15^{\text {th }}$ (referred to from here on as Tide 1 and Tide 2). The maximum water depths for Tide 1 and Tide 2 were $6.5 \mathrm{~m}$ and $6.3 \mathrm{~m}$ respectively. Wave heights and period were 
measured at the offshore wave buoy of $H_{s}=0.6 \mathrm{~m}$ and a $T_{p}=9.5 \mathrm{~s}$ for Tide 1 and $H_{s}=0.7 \mathrm{~m}$ and a $T_{p}=$ $10 \mathrm{~s}$ for Tide 2.

The morphology of the study area is shown in Figure 5. The rip channel is clearly defined by the mean low water spring (MLWS) position (bold line). It is aligned so that the channel is shore normal, and is situated between two sand bars. At its largest the rip was visually observed to be approximately $50 \mathrm{~m}$ wide and $150 \mathrm{~m}$ in length.

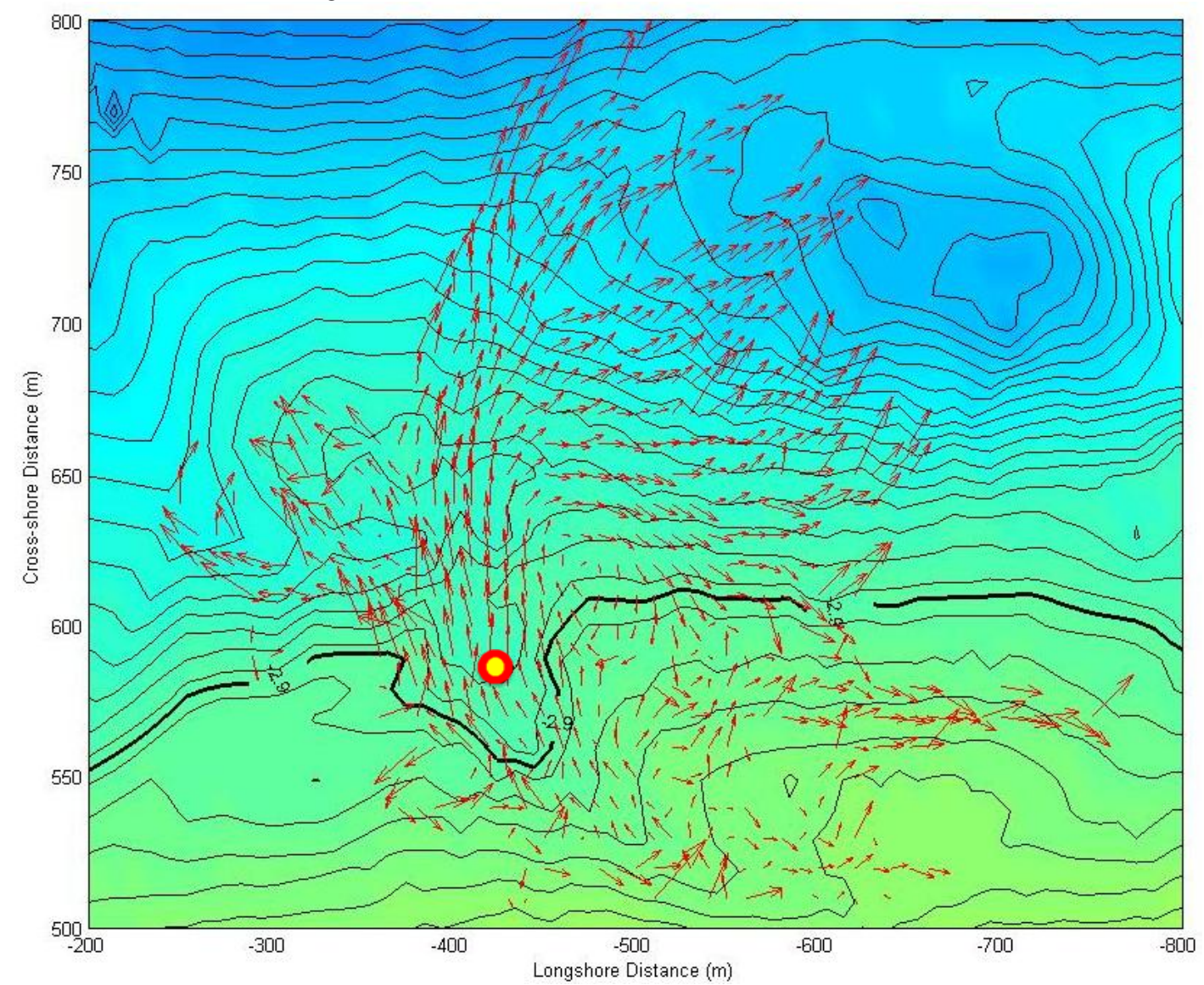

Figure 5: Beach morphology and averaged GPS drifter tracks from when bedform measurements in the rip were taken. The bold line represents the MLWS position; the circle indicates the rig position.

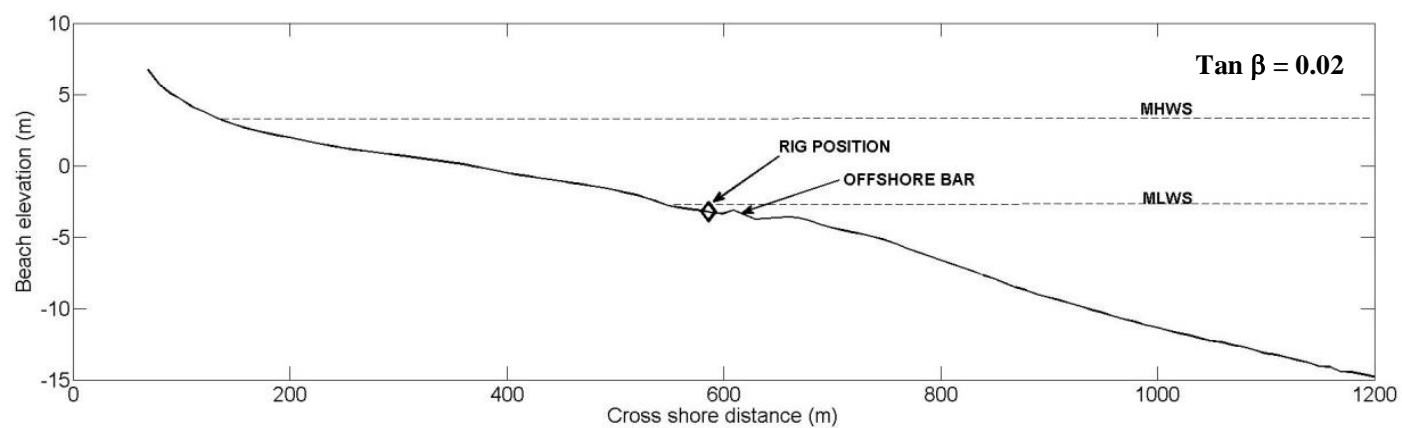

Figure 6: Beach profile through instrument position. Tan $\beta$ of 0.02 indicates a gently sloping beach.

To process the drifter data, the nearshore zone surrounding the rip system was divided into $10 \mathrm{~m} \mathrm{x}$ $10 \mathrm{~m}$ bins. The drifter observations (position and velocity) were averaged within each bin. Bins with over five drifter observations were deemed statistically significant. The resulting quiver plot is superimposed on the bathymetric map in Figure 5 and shows the rip flows in and around the rip system for approximately 2 hours either side of low tide. As $H_{s}$ was small, wave breaking was minimized on the bar allowing drifters to exit the surfzone and flow up to $250 \mathrm{~m}$ offshore of the MLWS position. There was also evidence of circulation (especially to the south) of the rip channel. At the position of the instrumentation, flow was directly offshore. 
In-situ hydrodynamic data are presented for Tides 1 and 2 as 10 minute means in Figure 7. The bedform dynamics are presented as three individual cases (Figure 8) chosen as they represent three distinct phases of bedform behaviour that are consistent throughout the whole data set. These cases are discussed in detail in the following section. The larger waves occurred in the ebb cycle of Tide 2 where $H_{s}$ exceeded $1 \mathrm{~m}$. At water depths of over approximately $2.5 \mathrm{~m}$ the mean flow is negligible. At all times in shallower water depths there is offshore flow at times reaching a maximum of $0.4 \mathrm{~m} / \mathrm{s}$. These are assumed to be rip current conditions; visual observations and comparison with lagrangian GPS drifter tracks support this assertion.
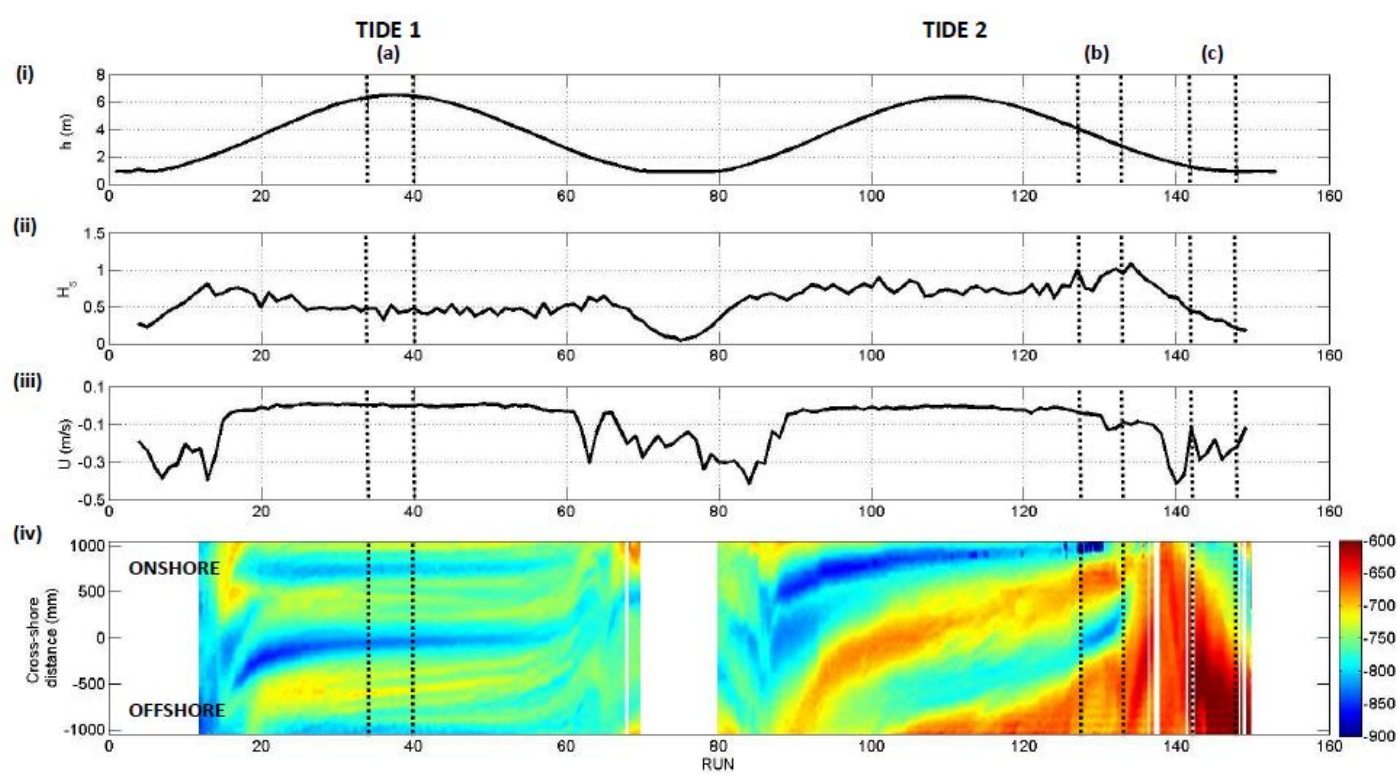

Figure 7: Time series over two tidal cycles of (i) $h(\mathrm{~m})$, (ii) $H_{s}(\mathrm{~m})$, (iii) $U(\mathrm{~m} / \mathrm{s})$ and (iv) bed evolution. The colour bar is a reference for the bed height as a measurement of the distance below the scanner $(\mathrm{mm})$. The three vertical bars mark out the high tide case $(a)$, mid tide $(b)$ case and rip current case $(c)$.

Plot $i v$ provides an overview of the bed and its evolution over time in relation to the hydrodynamic conditions. The 'hot' colours represent bedform crests and the 'cool' colours represent troughs. The blank spaces are where the water level was below the height of the SRP or where bubbles in the water inhibit the recording of the bed. Around high tide (represented by case $a$ ) stable (Tide 1) or slowly onshore migrating (Tide 2) bedforms of $\lambda=1-1.5 \mathrm{~m}$ occur in negligible mean flow and small waves. At mid tide (represented by case $b$ ), bedforms are of a similar size to those observed at high tide, but they migrate onshore at a much faster rate in weak offshore mean flow and larger waves. At lower tidal elevations, the instrument rig is in the rip current (small waves, strong offshore flow) and this is represented by case $c$. Under these conditions there is offshore migration of small features $(\lambda=\sim 0.5 \mathrm{~m})$ in the flood tide of Tide 2 and offshore migration of a much larger feature $(\lambda=\sim 3 \mathrm{~m})$ during the ebb tide. Bedform development during the three cases is discussed in more detail below.

\section{Bedform Results}

Each case ( $a, b$ and $c$ ) consists of one hour of data and is categorised based on tidal elevation as high tide (HT), mid tide (MT) and low tide (LT), with only the low tide case representing 'true' rip current conditions. The hydrodynamic conditions for each tide are presented in Table 1 . The high tide case is characterised by negligible flow and a relatively small velocity variance $\left(\sigma^{2}\right)$ and wave skewness $(S)$. Wave skewness was calculated following Elgar et al. (1988), see Equation 1 below. At high tide the conditions may be considered to be in a low energy state. As tidal elevation decreased towards mid tide, represented by case $b, H_{s}, S$ and $\sigma^{2}$ all increased, representing the transition to a higher energy state. During this time there was also a mean offshore flow of $0.07 \mathrm{~m} / \mathrm{s}$. As the tidal elevations fell further, the rip current became active and the values of $H_{s}, T_{p}, S$ and $\sigma^{2}$ decreased slightly, and offshore mean flow of $0.26 \mathrm{~m} / \mathrm{s}$ (upper 10 percentile of the mean flow $\left(U_{10}\right)$ of $0.42 \mathrm{~m} / \mathrm{s}$ ) became the dominant hydrodynamic process.

$$
S=\frac{<u(t)^{3}>}{<u(t)^{2}>^{3 / 2}}
$$




\begin{tabular}{|c|c|c|c|c|c|c|c|c|}
\hline \multicolumn{7}{|c|}{$\begin{array}{l}\text { Table 1: Summary of key hydrodynamic parameters } \\
\left(\boldsymbol{h}, \boldsymbol{H}_{\boldsymbol{s}}, \boldsymbol{T}_{\boldsymbol{p}}, \boldsymbol{U}, \boldsymbol{U}_{\boldsymbol{l}}, \boldsymbol{\sigma}^{2}, \text { and } \boldsymbol{S}\right) \text { for HT, MT and LT case }\end{array}$} \\
\hline Case & Location & $h(\mathrm{~m})$ & $H_{\boldsymbol{s}}(\mathrm{m})$ & $T_{p}(\mathrm{~s})$ & $U(\mathrm{~m} / \mathrm{s})$ & $U_{l 0}(\mathrm{~m} / \mathrm{s})$ & $\sigma^{2}\left(\mathrm{~m}^{2} \mathrm{~s}^{2}\right)$ & $S$ \\
\hline a & HT & 6.3 & 0.44 & 9.0 & 0.00 & -0.01 & 0.02 & 0.13 \\
b & MT & 3.3 & 0.90 & 10.0 & -0.07 & -0.12 & 0.12 & 0.80 \\
c & LT & 1.2 & 0.42 & 6.6 & -0.26 & -0.42 & 0.08 & 0.77 \\
\hline
\end{tabular}

(a)

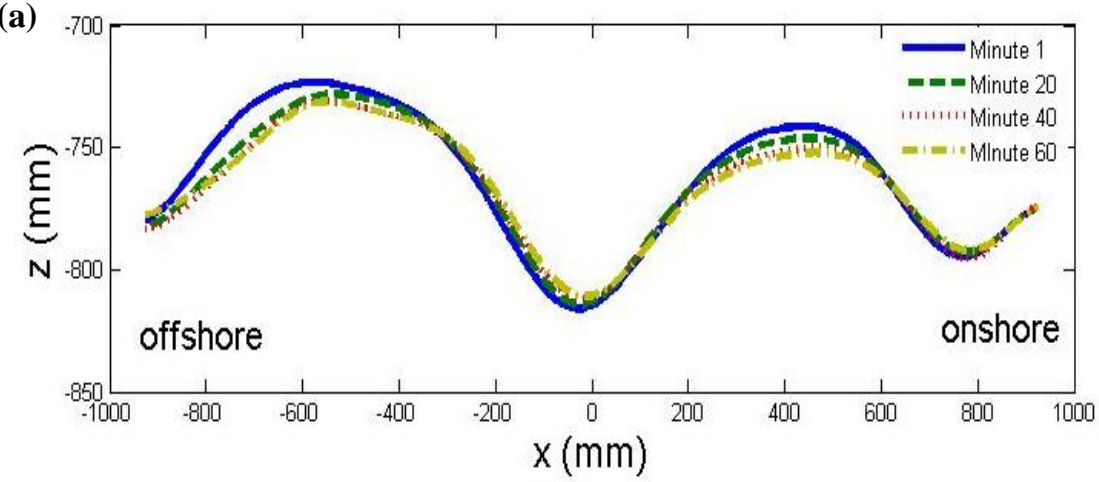

(b)

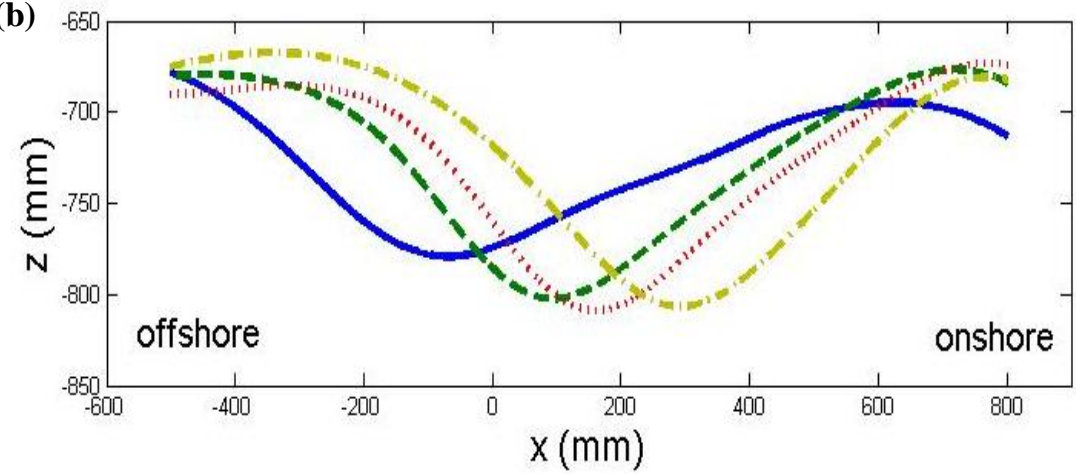

(c)

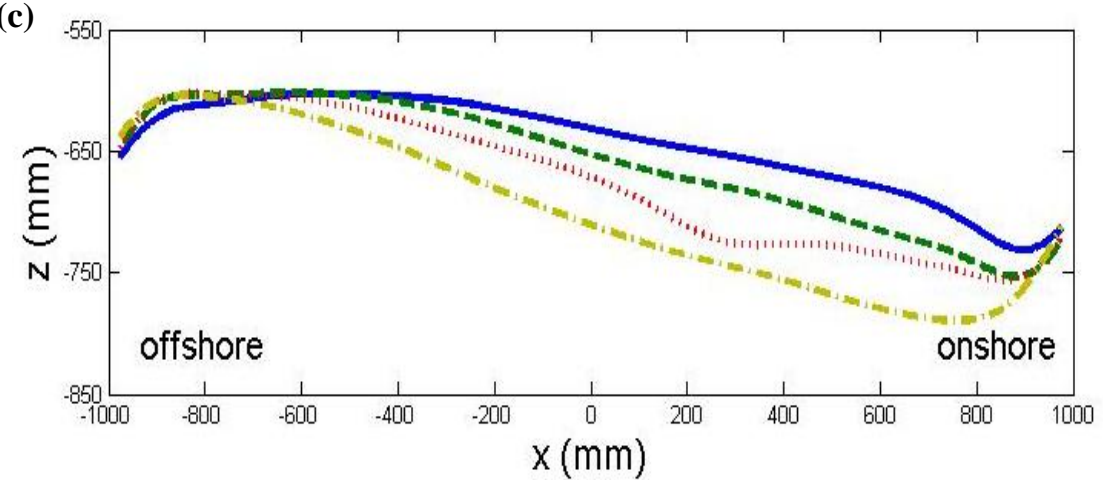

Figure 8: Individual bed scans at (a) high tide; (b) mid tide and (c) at low tide, 20 minutes apart over a one hour period. Note that the plots are not all of same scale.

Figure 8 shows the bed profiles derived from SRP scans for each identified case. During high $(a)$ and mid tide $(b)$ the bedforms appear to be symmetric and are at the lower end of the megaripple size range (during high tide: $\Delta=0.09 \mathrm{~m}, \lambda=1 \mathrm{~m}$; during mid tide: $\Delta=0.12 \mathrm{~m}, \lambda=1.20 \mathrm{~m}$ ). The main difference between these two cases is that at high tide the bed migrates very slowly onshore $\left(\mathrm{M}_{\mathrm{r}}=0.03\right.$ $\mathrm{m} / \mathrm{hr})$ and at mid tide there is significant onshore migration $\left(\mathrm{M}_{\mathrm{r}}=0.35 \mathrm{~m} / \mathrm{hr}\right)$. During low tide, when measurements are being made in the rip current, the bedform height and length increases significantly to approximately $0.15 \mathrm{~m}$ and $3 \mathrm{~m}$ respectively and the bedform migrates offshore at a rate of $0.21 \mathrm{~m} / \mathrm{hr}$. 


\begin{tabular}{|c|c|c|c|c|}
\hline \multicolumn{5}{|c|}{ Table 2: Summary of bedform dynamics } \\
$\left(\Delta, \lambda\right.$ and $\left.\boldsymbol{M}_{\boldsymbol{r}}\right)$ for HT, MT and LT cases. \\
\hline Case & Location & $\Delta(\mathrm{m})$ & $\lambda(\mathrm{m})$ & $M_{r}(\mathrm{~m} / \mathrm{hr})$ \\
\hline $\mathrm{a}$ & $\mathrm{HT}$ & 0.09 & 1.0 & 0.03 \\
$\mathrm{~b}$ & $\mathrm{MT}$ & 0.12 & 1.2 & 0.35 \\
$\mathrm{c}$ & $\mathrm{LT}$ & 0.15 & 3.0 & -0.21 \\
\hline
\end{tabular}

Figure 9 highlights the change in migration dynamics with respect to water level and mean crossshore velocity. Migration rate is calculated from individual scans 10 minutes apart of which the time of the first and last scan correspond to the start and end of each 'run' of hydrodynamic data. Negative migration is in the offshore direction. In the strong offshore flow of the rip current migration is offshore, at mid tide in weak offshore flows it is onshore, and at high tide it is very slow in the onshore direction. It appears that there is a threshold mean flow velocity of approximately $-0.2 \mathrm{~m} / \mathrm{s}$ around which the bedform migration changes direction, though it is likely that wave processes will affect this value.

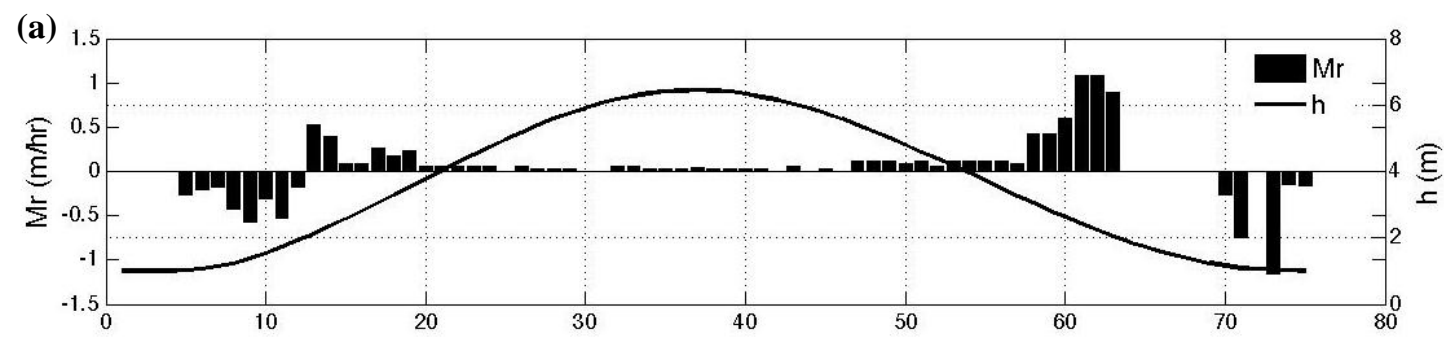

(b)

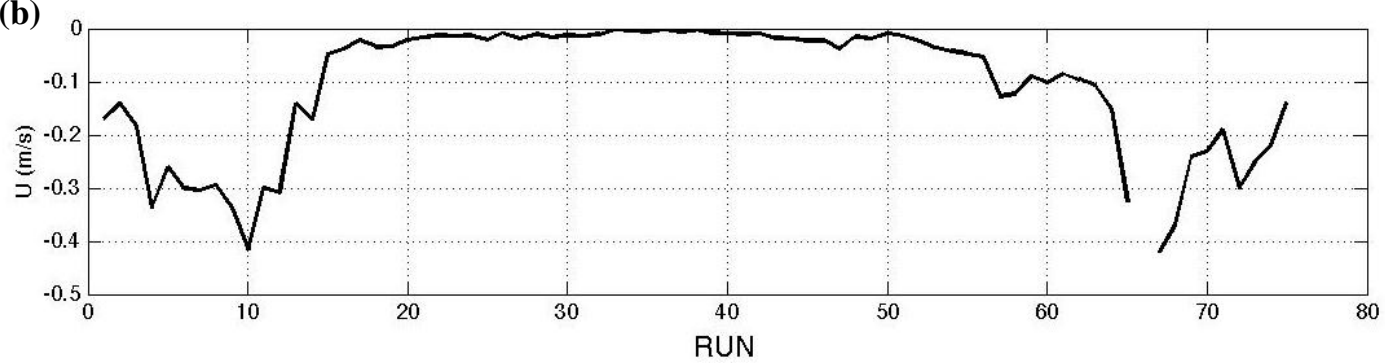

Figure 9: (a) Overview of migration rate $\left(M_{r}\right)$ and direction (-ve $=$ offshore) and rate in relation to water depth and (b) mean cross-shore velocity (taken from Tide 2 ).

\section{DISCUSSION}

Measurements of bedforms in a rip channel over a macro-tidal cycle have shown that there are a range of bedform behaviours and this appears to be in response to a variation in hydrodynamic conditions.

During active rip current conditions, measurements conformed well to observations reported in the literature (Aagaard et al., 1997; Brander, 1999b; Greenwood \& Davidson-Arnott, 1979; Nielsen, 1992). Bedforms were of megaripple dimension, migrated offshore and had an asymmetric profile. The change of the profile of the megaripples at the onset of strong offshore flow from symmetric to asymmetric (with the stoss face downstream of the flow origin) supports Nielsen's (1992) observation that they are current dominated. Though the asymmetric profile indicates a current dominated regime, comparison between migration rates in this study and results obtained by Sherman et al. (1993) in a feeder channel suggests that waves may still have an influence. Sherman et al. (1993) recorded average migration rates of $0.99 \mathrm{~m} / \mathrm{hr}$, compared to the $0.21 \mathrm{~m} / \mathrm{hr}$ recorded in this study at similar mean flow velocities (mean of $0.5 \mathrm{~m} / \mathrm{s}$ ). The key difference between these two environments is that in a feeder channel wave energy has been fully dissipated as waves break on the sandbar and that the current is generally at right angles to the wave direction, whereas in the rip waves propagate shoreward in opposition to the rip flow. This may have the effect of slowing the offshore migration of megaripples and may explain the difference in migration rates recorded in an otherwise similar environment.

Outside of rip current conditions the bedforms were observed to be symmetrical. Gallagher (2003) suggested this was due to the oscillatory motion of the waves. During the onshore stroke of a wave the sediment is moved shoreward along the ripple crest where it tumbles down the slip face into the trough. 
Flow separation occurs just prior to the beginning of the offshore stroke of the wave which creates turbulence and suspends sediment; the offshore stroke then transports sediment offshore. Due to sediment moving in both directions a symmetrical profile occurs. If the waves are skewed the onshore stroke of the wave is stronger than the offshore stroke resulting in net sediment transport occurring in the onshore direction. Gallagher (2003) proposed this may result in onshore migration of bedforms. An initial investigation into skewness and velocity variance suggests that these may influence bedform migration rates in the non-rip cases. At mid tide, high values of wave skewness and velocity variance coincided with onshore bedform migration. At high tide wave skewness and velocity variance were found to be much lower and subsequently bedform migration was very slow in the onshore direction or non-existent. This suggests that both skewness and velocity variance are important processes outside of active rip current conditions in terms of bedform migration dynamics even though at mid-tide there was a weak mean offshore flow opposing the migration direction.

The megaripple length scale was found to be up to three times greater in active rip currents compared to non-rip conditions. At this stage it appears that an increase in wavelength is a response to the onset of strong offshore flow. Hoekstra et al. (2004) described a similar result of rapid bedform growth with increasing current velocities.

The results presented here show megaripples migrating at significant rates in both the onshore and offshore directions. It has been suggested that this may be an important mechanism for sediment transport (Gallagher et al., 1998). The migration of small scale bedforms $(\Delta=0.015 \mathrm{~m}, \lambda=0.15 \mathrm{~m})$ (Kachel \& Sternberg, 1971) and larger scale features $(\Delta=0.4-0.1 \mathrm{~m}, \lambda=0.6-1.7 \mathrm{~m})$ (Hoekstra et al., 2004) have both been used as a proxy for bedload sediment transport.

In this study the net transport of the megaripples over a tidal cycle is a balance between onshore transport when the water is deep and the rip is not operating and offshore in the rip current when the water is shallow.

\section{CONCLUSIONS}

New measurements within a rip channel have found bedform dynamics to be dependent on waves, water depth and the occurrence of offshore directed flows in the rip channel. In an active rip current $\left(U_{10}=-0.41 \mathrm{~m} / \mathrm{s}\right.$ ) bedforms were found to be current dominated, exhibiting an asymmetric profile and migrating offshore $\left(M_{r}=-0.21 \mathrm{~m} / \mathrm{hr}\right)$. The increase in current velocity at the onset of rip current conditions also seems to have the effect of increasing megaripple length scale $(\Delta=0.15 \mathrm{~m}, \lambda=3 \mathrm{~m})$ by up to three times the lengths recorded in non-rip conditions $(\Delta=0.09-0.12 \mathrm{~m}, \lambda=1-1.2 \mathrm{~m})$. In nonrip conditions bedforms were observed to be symmetrical due to the back and forth movement of sediment driven by oscillatory wave motion. At mid tide skewed waves and an increased velocity variance appear to induce significant onshore megaripple migration $\left(M_{r}=0.35 \mathrm{~m} / \mathrm{hr}\right)$, which was reduced at high tide $\left(M_{r}=0.03 \mathrm{~m} / \mathrm{hr}\right)$ when wave skewness and velocity variance decreased.

\section{REFERENCES}

Aagaard, T., Greenwood, B. \& Nielsen, J. 1997. Mean currents and sediment transport in a rip channel, Marine Geology, 140 (1-2), 25-45.

Austin, M., Scott, T., Brown, J., Brown, J., MacMahan, J., Masselink, G. \& Russell, P. 2010. Temporal observations of rip current circulation on a macro-tidal beach, Continental Shelf Research, 30 (9), 1149-1165.

Brander, R. W. 1999a. Field observations on the morphodynamic evolution of a low-energy rip current system, Marine Geology, 157 (3-4), 199-217.

Brander, R. W. 1999b. Seiment Transport in Low Energy Rip Current Systems, Journal of Coastal Research, 15 (3), 839-849.

CCO 2012. Channel Coast Observatory, [Online]. Available at: http://www.channelcoast.org/data_management/real_time_data/charts/?chart=76 (Accessed: 23/11/2011).

Elgar, S., Guza, R. T. \& Freilich, M. H. 1988. Eulerian Measurements of Horizontal Accelerations in Shoaling Gravity Waves, Journal of Geophysical Research, 93 (C8), 9261-9268.

Gallagher, E. L. 2003. A note on megaripples in the surf zone: evidence for their relation to steady flow dunes, Marine Geology, 193 (3-4), 171-176.

Gallagher, E. L., Elgar, S. \& Thornton, E. B. 1998. Megaripple migration in a natural surf zone, Nature, 394 (6689), 165-168.

Greenwood, B. \& Davidson-Arnott, G. D. 1979. Sedimentation and equilibrium in wave-formed bars: a review and case study, Journal of Earth Science, 312-332. 
Hoekstra, P., Bell, P., van Santen, P., Roode, N., Levoy, F. \& Whitehouse, R. 2004. Bedform migration and bedload transport on an intertidal shoal', Continental Shelf Research, 24 (11), 1249-1269.

Kachel, N. B. \& Sternberg, R. W. 1971. Transport of bedload as ripples during an ebb current', Marine Geology, 10 (4), 229-244.

MacMahan, J. H., Thornton, E. B. \& Reniers, A. J. H. M. 2006. Rip current review, Coastal Engineering, 53 (2-3), 191-208.

MacMahan, J. H., Thornton, E. B., Stanton, T. P. \& Reniers, A. J. H. M. 2005. RIPEX: Observations of a rip current system, Marine Geology, 218 (1-4), 113-134.

Nielsen, P. 1992. Coastal bottom boundary layers and sediment transport. Advanced series on ocean engineering. London: World Scientific.

Schmit, W. B., Woodward, K., Millikan, R., Guza, R. T., Raubenheimer, B. \& Elgar, S. 2003. A GPStracked surf zone drifter, Journal of Atmospheric and Ocean Technology, 1069-1075.

Sherman, D. J., Short, A. D. \& Takeda, I. 1993. Seiment Mixing-Depth and Bedform Migration in Rip channels, Journal of Coastal Research, 39-48. 